\title{
Factors Predicting Spiritual Well-Being among Dependent Older People
}

\author{
Doungmon Trapsinsaree, Linchong Pothiban*, \\ Rojanee Chintanawat and Tipaporn Wonghongkul
}

\author{
Faculty of Nursing, Chiang Mai University, Chiang Mai 50200, Thailand
}

('Corresponding author's e-mail: linchong.p@cmu.ac.th)

Received: 18 August 2020, Revised: 5 April 2021, Accepted: 18 May 2021

\begin{abstract}
Spiritual well-being is a deep feeling within the mind that represents peacefulness and the inner strength of individuals, resulting from an understanding of the nature of life and acceptance of changes occurring to themselves. Spiritual well-being is; therefore, very important to dependent older people. The objectives of this study were to identify the levels of spiritual well-being of dependent older people, to examine the relationships between religious belief, religious practice, self-esteem, social support, depression, and spiritual well-being, and to examine the ability of those factors to predict spiritual wellbeing among dependent older people. The study sample were 395 of people aged 60 years and above who are dependent and live in three provinces in southern Thailand. Data were collected using questionnaires, including the Spiritual Well-Being Scale for Dependent Older People, Thai version of the Rosenberg Self-Esteem Scale, Thai version of the Multidimensional Scale of Perceived Social Support, Thai Geriatric Depression Scale, the Religious Practices Questionnaire, and the Buddhist Belief Questionnaire. Data were analyzed using descriptive statistics, Spearman's rank correlation coefficient, and multiple regression analysis. The study results were as follows: 1) The spiritual well-being among dependent older people was at a moderate level $(\overline{\mathrm{x}}=46.97, \mathrm{SD}=7.22) .2)$ Religious belief, religious practice, self-esteem, and social support significantly related positively to spiritual well-being $(p<0.01)$, while depression significantly related negatively to spiritual well-being $(p<0.01)$. 3) Religious belief, self-esteem, and social support together could explain $46.00 \%$ of the variance in spiritual well-being. The results of this study can be used by nurses and health care providers to determine interventions for enhancing spiritual well-being in this particular group of older people.
\end{abstract}

Keywords: Spiritual well-being, Dependent older people, Dependent, Older people

\section{Introduction}

The number of older persons in the world has increased substantially in recent years. There were 990 million people aged 60 years or over in 2018, and by 2050, 1 in $6(16 \%)$ people in the world will be over age 65 [1]. In Thailand, the number of older persons aged 60 and over has grown rapidly and will continue to do so in future decades. In 2018, Thai older people age 60 and over were 12 million persons, which was accounted for $17.6 \%$ of the entire Thai population and estimated that the population of people will increase by $20 \%$ in four years. It means, Thailand will become a completed age society in that year. Recently, Thailand was ranked in the second country had number of older people more than others in ASEAN. Most (57.4\%) of the older people in Thailand are 60 to 69 years of age. The late older people population (aged 80 and over) will increase dramatically from 1.5 million in 2017 to 3.5 million in the next 20 years [2]. This group of older people is known to have some physical disability, and they are more likely to be dependent, which are estimated 400,000 dependent older people in Thailand [3].

The older people mostly are dependent due to their limited physical condition, which results from chronic diseases and age-related degeneration. Currently approximately $71 \%$ of dead of older people were from chronic disease [4]. The older people need assistance from caregivers to accomplish daily activities to meet their basic needs as well as need love, warmth, and security [5]. Dependency causes the older people to lose their self-value, power, happiness, and causes a feeling of hopelessness. According to a study of suffering among older people with chronic diseases, serious illness, degeneration of the body, and dependence on family members are the main causes of suffering. However, these people have suffering physically, but they retain psychosocial well-being. Therefore, dependency can affect people's well-being thus health care providers should pay attention to the dependent older people's well-being. Although the 
physical condition of dependent older people cannot be restored to their original state, relief of suffering and the promotion of spiritual well-being will help the older people live a balanced life and overcome suffering.

Spiritual well-being is known as the most essential resource for achieving the person's well-being. It integrates the person's spiritual dimension with other health dimensions (that is, physical, psychological, and social dimensions) for holistic health [6]. Spiritual well-being can also be defined as the person's ability to develop his or her spiritual nature to its fullest potential, which inspires a search for meaning and purpose in life and a search for the supernatural or for some meaning that transcends oneself [7]. There is no single definition of spiritual well-being, because it varies according to one's perspective. It is defined in many ways both from Western and Eastern perspectives. From the Western perspective, spiritual well-being is defined in a variety of ways. It was defined as a developmental personality characteristic that is associated with a sense of inner peace, compassion for others, and reverence for life [8] and as an individual's perception of well-being within two spiritual dimensions, that is, religious and existential. The religious dimension of spirituality represents a sense of well-being related to God, whereas the existential dimension reflects a sense of life-purpose and satisfaction [9]. Similarly, Wilber (1995) defined spiritual health as the drive of spirit, that is, as living to one's potential in accepting and loving oneself and finding meaning in life, which is an expression of increasing self-realization. This can help people to grow in wisdom, to become more creative, and to use their emotions in a healthy manner. The spiritual well-being in the Western perspective mainly focus on ability to develop one's spiritual nature to its fullest potential, which emphasizes a sense of connection with God and a sense of meaning and purpose in life, inner peace, compassion for others, and life satisfaction.

From the Eastern perspective, religion influences every aspect of the individual's life, especially spiritual well-being. Buddhism is the main religion in many East Asian countries. It emphasizes the balanced interaction between the mind and body and between one's life and environment. From the Buddhist perspective, spiritual well-being is the happiness that comes from living with wisdom, which is knowledge, thought, and belief. Spiritual well-being occurs when a person does good deeds or touches the highest value, such as benevolence, access to the Triple Gem, or reaching the ultimate goal according to religious beliefs [10]. Similarly, spiritual well-being means a state of mind that is happy and peaceful. Peace-fullness is caused by goodness, unselfishness, and intellectually understanding that the nature of life consists of three components: 1) peace and happiness that comes from goodness, unselfishness, and having the four principles virtuous existence, 2) feeling joyful in performing duties and living, and 3) consciousness, concentration and wisdom [11].

Thais mostly define spiritual well-being based on Buddhist doctrine. Spiritual well-being is viewed as a deep feeling within a person's mind that indicates a state of peace, happiness, strength in the mind, accept the truth, having goal in life, hope and satisfaction with who they are [12]. It is also defined as a state of happiness and satisfaction in one's life, having faith and religious practice, being of value and awareness in human being, having lovingkindness and compassion to humankind and others, including ability to maintain one's life associated with the changing of environment and society [13]. Moreover, a research that defined spiritual well-being for Thai Buddhist adults with chronic illness as a state of understanding self and nature of life, being peaceful, being happy, having a sense of connectedness, and having hope [14]. In conclusion, literature shows a similar definition of spiritual well-being as a state of happiness and satisfaction in one's life, understanding self and the nature of life, being peaceful, having sense of connectedness, and having hope. Buddhism can lead to a state of spiritual well-being.

For health care, spiritual well-being is one of the important dimensions of holistic care. Spiritual well-being has a positive effect on physical, mental and social health [15]. Spiritual well-being makes the older people have power to heal themselves, accept health conditions and change expectations. The older people were able to live worthily and truly understand life. Therefore, the enhancement of spiritual wellbeing of dependent older people can be done when the health care provider knows about the factors that influence spiritual well-being. Previously, no study about the factors related to spiritual well-being in dependent older people had been reported. However, studies among people with chronic illness found that spiritual well-being was at a high or moderate level. Among those studies, the tools for measuring spiritual well-being were developed from Western culture whose population are Christian. Using those tools made the researcher to miss information obtained. As the majority of Thailand's population is Buddhist (93 \%), their views about spiritual well-being might be different from other groups. In Buddhism, each individual consists of body and mind. When the body has deteriorated physically, an individual must rely on other people, and anxiety, depression, insecurity, and self-esteem decreases, thus causing more suffering.

For dependent older people, to make them feel well, their spiritual well-being must be enhanced. Knowledge about the factors that influence well-being, therefore, is vital. According to a literature 
review, there is no study of factors related to spiritual well-being of dependent older people, but studies have been made in chronic illnesses such as cancer. Those studies found that the related factors were social support, religious practice, depression, and functional ability [16]. In addition, the factors related to spiritual well-being should be consistent with the attitude and beliefs about spiritual well-being of the sample. For the majority of dependent older people in Thailand, who are Buddhists, religion has a great influence on life. Moreover, Buddhists believe that a human life happens as a co-existence of body and mind. For example, if a wise person understands the truth, the mind is not suffering. From the literature review and the application of Buddhist principles, this study found that the factors that may influence spiritual well-being are religious belief, religious practice, self-esteem, social support, and depression.

Religious belief is the attitude toward various aspects of a particular religion that is demonstrated in the daily life of the believer. The teachings of the Buddha can be used in life to make that person understand the suffering or illness that has occurred. The strong religious beliefs make older people adjust with their limitations. Therefore, religious belief was used as a variable in the study of spiritual wellbeing. Religious practices following Buddhist doctrine are indicators of ways of life that make people calm, relieve suffering, have a true understanding of life and the world, live a conscious life and live with value [12]. In the past, the relationship was found that religious practices have a positive relationship with spiritual well-being and predict spiritual well-being [17]. In the present study, the variable of religious practices refers to the practices based on the Buddhist doctrine including giving alms, keeping the precepts, and prayers. Namely, practicing according to the religious way, doing evil and harassing others will be stopped. The experienced person will be conscious in his or her mind with training and understanding the truth of life. Actually, the religious practices make the people stronger, accepting mentally, and satisfied with each person's current physical condition. Religious practices according to the word of Buddhist were used as the factor to study in spiritual well-being.

Self-esteem is a judgment of self-worth and is expressed in the form of a person's attitude towards themselves. Self-esteem is a perspective, concept, and attitude of a person towards themselves in a positive or negative direction, that is, a person with self-esteem feels that he or she is valuable due to their selfsatisfaction. In addition, self-esteem enables people to face the obstacles in their lives and be able to handle them. From the literature review, there have been studies that found the process of adding value to oneself, according to the Buddhist teaching, causes the people to improve their lives to becoming virtuous [18] and thus causing spiritual well-being. In the present study, the variable of self-esteem is taken from the principles of Buddhism's Four Noble Truths. Belief in the Four Noble Truths is a way that reduces the suffering, insight the truth based on cause and effect, can see way to solve the problems. Thus, Noble Eightfold Path's belief causes a person to live with good morals and they become more proud and aware of their values.

The variable of social support refers to the person's perception of receiving assistance when needed from others, that is, emotional support, information, and material assistance. Perceived social support reflects the person's relationship with other people and leads to satisfaction with life. The doctrines of Buddhism include teachings related to social support that has six directions. The Buddha divided the relationships of individuals in society into six groups, comparing the relationships with other persons to six directions (that is, parents in East, teachers in South, wife in West, and friends and colleagues in North, ascetics and Brahmins in Up, and the servants in Down) and thereby determining the person's duty to interact with each other and to be generous and supportive to each other. Therefore, social support was used as a variable in the study of spiritual well-being.

The variable of depression refers to the condition of feeling bad and having negative thoughts toward the self. Depression was found to relate negatively to spiritual well-being of older people with diabetes [19]. In Buddhism, depression is suffering (dukkha). Suffering can be divided into 2 categories: Physical and mental. People also suffer when they are unable to satisfy their limitless needs and wants. If suffering diminishes, there would be no depression, and happiness would replace it. According to Buddhism principles, less suffering (from consideration of suffering) will give a person a way to end suffering and create spiritual well-being. Therefore, depression was used as a variable in the study of spiritual well-being.

From a literature review, there was little knowledge of spiritual well-being and the associated factors in dependent older people. The researcher, therefore, would like to explore level of spiritual well-being in dependent older people and examine the relationship between the selected factors and spiritual well-being in this particular group. This study's results are the information for further research and intervention for promoting spiritual well-being that will help dependent older people live their lives with happiness. 


\section{Materials and methods}

The research design of this study was a descriptive predictive design aiming to examine whether religious belief, self-esteem, religious practice, functional ability, social support, and depression can predict spiritual well-being among dependent older people. The target population of this study consists of Thai people aged 60 years and above who met the criteria for being dependent. The accessible populations were those living in the lower southern region of Thailand, consisting of 3 provinces including Songkhla, Trang, and Phatthalung. The sample for this study was the dependent older people who met the following inclusion criteria:

1. Being Buddhist.

2. Having good cognition assessed by Mental Status Questionnaire [20] which the score was 8 or more.

3. Having limited ability to perform activities of daily living assessed by the Barthel Index of $\leq 11$ (0 - 4 total dependency, 5 - 8 severe dependency, and 9 - 11 moderately severe dependency)

4. Being able to communicate verbally in Thai, and willing to participate in this study.

The sample size in this study was estimated using Yamane's formula [21]. This study determined the level of precision at $95 \%$, or a significant level $\alpha$ of .05 , the population size was 3,450 dependent older people. Thus, the estimated sample size was 358. In addition, the sample size should be added by $10 \%$ in order to prevent missing data considering. Therefore, the possible complete data was 395 participants. A Multi-stage random sampling method was used to select participants. Three provinces from seven provinces of the lower southern region of Thailand were randomly selected, including Songkhla, Trang, and Phatthalung. Within each province, 3 - 4 districts were randomly selected, total of 10 districts. There were 3 districts from Trang province, 3 districts from Phatthalung province, and 4 districts from Songkhla province. Within each district 2 subdistricts were randomly selected, total 20 subdistricts, and 1 Tambon Health Promoting Hospital in the subdistrict was recruited. The subjects were purposively selected based on the inclusion criteria of 395 participants. Finally, the number of participants was calculated based on the number of dependent older people in the subdistrict.

\section{Research instruments and validity test}

1. The Demographic Data Form was developed by the researcher for gathering the elderly's demographic data including gender, age, marital status, education, income, and living arrangement.

2. The Spiritual Well-Being Scale for Dependent Older People that modified from Spiritual WellBeing Scale for Thai Buddhist Adults with Chronic Illness was used to measure [14]. The questionnaire consists of 13 items. The items use a 5-point Likert scale with responses from strongly disagree (1) to strongly agree (5). This instrument has three components which are 1) having hope and sense of connectedness (5 items), 2) understand yourself and nature of life (4 items), and 3) peacefulness (4 items). The possible score ranged from 13 to 65 . A high score indicated a high degree of spiritual well-being. The total score was classified into three equal levels including low (13 - 30), moderate (31 - 48), and high (49 $65)$. In this study, the internal consistency reliability of this instrument was tested with 15 dependent older people. The Cronbach's alpha coefficient was 0.91 .

3. The Rosenberg Self-Esteem Scale was developed by Rosenberg (1965) and translated into Thai by Srisaeng [22] and used for measuring self-esteem among older people in this study. The questionnaire consists of 10 items. The items use a 4 - point Likert scale with responses from strongly agree (1) to strongly disagree (4). The higher score showed better self-esteem. The questionnaire contained 8 items for asking feeling of self-value and self-respect and 2 items for the feeling of competence. The possible score ranges from 10 - 40. In this study, the internal consistency reliability of this instrument was tested with 15 dependent older people. The Cronbach's alpha coefficient was 0.89 .

4. The Multidimensional Scale of Perceived Social Support (MSPSS) was developed by Zimet and colleagues (1988) and translated into Thai by Boonyamalik and used to measure perceiving social support with dependent older people [23]. The instrument consists of 12 items. The items use a 7-point Likert scale with responses from very strongly disagree (1) to very strongly agree (7). The possible score ranged from 12 - 84. In this study, the internal consistency reliability tested with 15 dependent older people showed the Cronbach's alpha coefficient of 0.89 .

5. The Thai Geriatric Depression Scale (TGDS) was developed from Geriatric Depression Scale by Train the Brain Forum Committee [24]. The instrument consists of 30 items. The items contained 10 positive questions and 20 negative questions. The answer "yes" to the positive questions were scored 0 , and the answer "no" were scored 1. In contrast, the answer for the negative questions were reversed the score. As a result, the total score was classified into four equal levels including no depression $(0-12)$, mild 
depression (13 - 18), moderate depression (19 - 24), and severe depression (25 - 30). In this study, internal consistency reliability of this instrument was tested on 15 dependent older people showed the KuderRichardson coefficient of 0.80 .

6. The Religious Practices Questionnaire was developed by Chaichanawirote [16]. The instrument consists of 20 items. The items contained 13 positive questions and 7 negative questions. The answers for the positive questions range from $1-3$, the answer "1" were 1 score, the answer " 2 " were 2 scores, and the answer " 3 " were 3 scores. In contrast, the answer for the negative questions were reversed the score. As a result, the total score was classified into three equal levels including low religious practices (1.00 - 1.66 scores), moderate religious practices (1.67 - 2.33 scores), and high religious practices $(2.34-3.00$ scores). In this study, the internal consistency reliability tested with 15 dependent older people showed the Cronbach's alpha coefficient of 0.89 .

7. The Buddhist Belief Questionnaire was developed by Seesopon et al. [25]. The instrument consists of 18 items. The items use a 5-point Likert scale with responses from slightly agree (1) to strongly agree (5). The questionnaire had 2 components: The belief in four components of saddhā (14 items) and the belief in the 3 characteristics of existence (4 items). The possible score ranged from 18 to 90 . A higher score indicated higher levels of religiousness. The total score was classified into three equal levels include low (18 - 42), moderate (43 - 66), and high (67 - 90). In this study, the internal consistency reliability tested with 15 dependent older people showed the Cronbach's alpha coefficient of .88

8. The Barthel Index was developed by Mahoney and Barthel [26]. The instrument consists of 10 items including feeding, grooming, transferring in and out of bed or chair, movement, climbing stairs, bathing with sponge or shower, dressing, toilet use, urine and bowel continence. The possible score ranged from 0 - 20 that low score indicated increasing disability. In this study, the internal consistency reliability tested with 15 dependent older people showed the Cronbach's alpha coefficient of 0.89 .

\section{Data collection}

This study was approved by the research committee of Faculty of Nursing, Chiang Mai University. The researcher conducted the data collection as follows:

1. The researcher sent self-introduction letter from the dean of Faculty of Nursing, Chiang Mai University to the Provincial Public Health Heads in Songkhla, Trang, Phatthalung province as well as the district Public Health Heads to clarify the purpose of the research and request permission to collect data according to procedures.

2. After receiving the approval letter, the researcher met the director of Tambon Health Promoting Hospital to elucidate the objectives of the research, data collection procedures, and request the cooperation in research and perform data collection.

3. The researcher reviewed medical records in order to get the list of dependent older people and selected prospective participant based on selection criteria.

4. The researcher met the dependent older people at home with the assistance from staff of Health Promoting Hospital. To avoid undue inducement, the researcher and hospital staff avoided dressing the uniform which showed that they were public health officer. The researcher introduced herself to the prospective participant and evaluated their qualifications based on the inclusion criteria. If they were qualified risk participation from the researcher informed them about the study, objectives, details of the research, and ask the participant to sign the consent form. Then, the researcher made an appointment to collect data of the participants at their homes. On the appointment date, the researcher administered seven questionnaires starting orderly from Demographic data form, Spiritual Well-Being Scale for dependent older people, The Rosenberg Self-Esteem Scale, The Multidimensional Scale, Thai Geriatric Depression Scale, The Religious Practices Questionnaire, and The Buddhist Belief Questionnaire. Meanwhile, the researcher allowed the participant to take a 10-min break if they preferred, questionnaires take time about $1 \mathrm{~h} 15 \mathrm{~min}$ per 1 participant.

5. The researcher or the research assistants rechecked the completion of all questionnaires and thanked the participants for their participation. A research assistant of this study was trained for collecting reliable data. The researcher selected a research assistant, who is a registered nurse and has experience in conducting research.

\section{Data analysis}

1. The demographic data were analyzed using descriptive statistics including frequency and percentage.

2. Spearman's rank correlation coefficient was used to determine the relationship between religious belief, religious practice, self-esteem, social support, depression, and spiritual well-being. 
3. Testing the predictability of religious belief, religious practice, self-esteem, social support, and depression on spiritual well-being of dependent older people were conducted.

3.1 Testing of linearity and homoscedasticity. Two assumptions were tested through the scatter plots of the standardized residuals by the regression standardized predicted value [27]. The result showed that the standardized predicted values were equally scattered around the 0 -axis of the residual. Therefore, the assumption of the linearity and homoscedasticity were met.

3.2 Testing of multicollinearity. Multicollinearity was analyzed between the predictor variables. There were three statistics used, including a correlation matrix of the independent variables, a Tolerance and the Variance-inflation factors (VIF) test. The tolerance coefficients ranged from $0.58-0.74$, which was above 0.10 and the VIF ranged from 1.35 - 1.72, which was less than 10. All values revealed no multicollinearity among predictor variables. Thus, the assumption of the multicollinearity was met. After testing for the assumptions, predictability of the religious belief, religious practice, self-esteem, social support, and depression on spiritual well-being of dependent older people was analyzed using multiple regression analysis.

\section{Results and discussion}

Demographic characteristics of the sample

The sample in this study consisted of 395 Thai older people with dependency. The findings showed that the majority of the participants in this study were female $(65.30 \%)$. The age of the participants ranged from 60 to 92 years. Among these participants, the majority age group was late older people (80 - 89 years) (41.30\%). Most participants had primary school education $(76.50 \%)$, and living arrangement had living with spouse and children $(68.40 \%)$. Regard to perceived income sufficiency, $55.70 \%$ of the participants had insufficient income. Their monthly family incomes were $<5,000$ Baht (76.50\%) (Table 1).

Table 1 Demographic characteristics of the sample $(\mathrm{N}=395)$.

\begin{tabular}{|c|c|c|}
\hline Demographic Characteristics & $\mathbf{n}$ & $(\%)$ \\
\hline \multicolumn{3}{|l|}{ Gender } \\
\hline Male & 137 & $(34.7)$ \\
\hline Female & 258 & $(65.3)$ \\
\hline \multicolumn{3}{|c|}{ Age (Range $60-92$ years, $\bar{x}=79.19$ years, $S D=8.02$ years) } \\
\hline $60-69$ & 52 & $(13.1)$ \\
\hline $70-79$ & 129 & $(32.7)$ \\
\hline $80-89$ & 163 & $(41.3)$ \\
\hline 90 and over & 51 & $(12.9)$ \\
\hline \multicolumn{3}{|l|}{ Marital status } \\
\hline Single & 173 & $(43.8)$ \\
\hline Married & 23 & $(5.8)$ \\
\hline Windowed & 188 & $(47.6)$ \\
\hline Divorced / Separated & 11 & $(2.8)$ \\
\hline \multicolumn{3}{|l|}{ Educational level } \\
\hline Unschooled & 62 & $(15.7)$ \\
\hline Primary school & 302 & $(76.5)$ \\
\hline Secondary school & 13 & $(3.3)$ \\
\hline Diploma & 10 & $(2.5)$ \\
\hline Bachelor & 8 & $(2.0)$ \\
\hline \multicolumn{3}{|l|}{ Living arrangement } \\
\hline Living alone & 22 & $(5.6)$ \\
\hline Living with spouses & 23 & $(5.8)$ \\
\hline Living with spouse and children & 270 & $(68.4)$ \\
\hline Living with others & 80 & $(20.2)$ \\
\hline \multicolumn{3}{|l|}{ Perceived income sufficiency } \\
\hline Sufficient income & 175 & $(44.3)$ \\
\hline Insufficient income & 220 & $(55.7)$ \\
\hline \multicolumn{3}{|l|}{ Income (Baht per month) } \\
\hline$<5,000$ & 302 & $(76.5)$ \\
\hline $5,001-10,000$ & 54 & $(13.7)$ \\
\hline
\end{tabular}




\begin{tabular}{ccc}
\hline Demographic Characteristics & $\mathbf{n}$ & $\mathbf{( \% )}$ \\
\hline $10,001-15,000$ & 29 & $(7.3)$ \\
$15,001-20,000$ & 10 & $(2.5)$ \\
$>20,000$ & 0 & $(0)$ \\
Barthel Index & & \\
$0-4$ & 47 & $(11.9)$ \\
$5-8$ & 100 & $(25.3)$ \\
$9-11$ & 248 & $(62.8)$ \\
\hline
\end{tabular}

\section{Descriptions of the study variables}

Data analysis revealed that the mean score of spiritual well-being is at a moderate level. The mean score of religious practice and self-esteem were at a moderate level, while the scores of religious belief and social support were at high level. The mean scores of depression was low with the mean of 11.37 (SD $=6.68$ ) that mean the participants did not have depression (Table 2).

Table 2 Possible score, actual score, mean, standard deviation, and level of study variables $(\mathrm{N}=395)$.

\begin{tabular}{lccccc}
\hline \multicolumn{1}{c}{ Variables } & Possible score & Actual score & Mean & SD & Level \\
\hline Spiritual well-being & $13-65$ & $28-65$ & 46.97 & 7.22 & Moderate \\
Religious belief & $18-90$ & $35-90$ & 77.69 & 9.23 & High \\
Religious practice & $20-60$ & $30-58$ & 42.77 & 4.86 & Moderate \\
Self-esteem & $10-40$ & $20-37$ & 27.56 & 2.82 & Moderate \\
Social support & $12-84$ & $31-84$ & 64.82 & 9.45 & High \\
Depression & $0-30$ & $0-29$ & 11.37 & 6.68 & Low \\
\hline
\end{tabular}

When classifying all variables into levels of low, moderate, and high, most participant (57.20\%) were in the moderate level of spiritual well-being and less than $1 \%$ were in low spiritual well-being. The highest percentage of participants had a moderate level of the religious practice $(75.90 \%)$ and self-esteem $(86.10 \%)$, and had a high level of religious belief $(91.10 \%)$ and social support $(72.90 \%)$. Regarding depression, the highest percentage of participants were at low level $(83.80 \%)$ (Table 3).

Table 3 Level of study variables $(\mathrm{N}=395)$.

\begin{tabular}{lccr}
\hline \multicolumn{1}{c}{ Variables } & Low & Moderate & High \\
\cline { 2 - 4 } & $\mathbf{n ~ ( \% )}$ & $\mathbf{n}(\mathbf{\%})$ & $\mathbf{n}(\mathbf{\%})$ \\
\hline Spiritual well-being & $3(0.80 \%)$ & $226(57.20 \%)$ & $166(42.00 \%)$ \\
Religious belief & $3(0.80 \%)$ & $32(8.10 \%)$ & $360(91.10 \%)$ \\
Religious practice & $10(2.50 \%)$ & $300(75.90 \%)$ & $85(21.50 \%)$ \\
Self-esteem & $3(0.80 \%)$ & $340(86.10 \%)$ & $52(13.20 \%)$ \\
Social support & $4(1.00 \%)$ & $103(26.10 \%)$ & $288(72.90 \%)$ \\
Depression & $33(83.80 \%)$ & $49(12.40 \%)$ & $15(3.80 \%)$ \\
\hline
\end{tabular}

\section{Relationships among study variables}

Data showed all variables were significantly related to spiritual well-being. The relationship was moderately positive between spiritual well-being and self-esteem $(\mathrm{r}=0.43, p<0.01)$, social support $(\mathrm{r}=$ $0.55, p<0.01)$, religious practices $(\mathrm{r}=0.42, p<0.01)$, and religious belief $(\mathrm{r}=0.39, p<0.01)$, whereas the relationship between spiritual well-being and depression was moderately negative $(\mathrm{r}=-0.40, p<$ 0.01) (Table 4). 
Table 4 Relationships between selected factors and spiritual well-being.

\begin{tabular}{lcccccc}
\hline \multicolumn{1}{c}{ Variables } & $\mathbf{1}$ & $\mathbf{2}$ & $\mathbf{3}$ & $\mathbf{4}$ & $\mathbf{5}$ & $\mathbf{6}$ \\
\hline 1. Spiritual well-being & 1 & & & & & \\
2. Self-esteem & $0.425^{* *}$ & 1 & & & & \\
3. Social support & $0.548^{* *}$ & $0.271^{* *}$ & 1 & & & \\
4. Depression & $-0.397^{* *}$ & $-0.445^{* *}$ & $-0.252^{* *}$ & 1 & & \\
5. Religious practices & $0.423^{* *}$ & $0.301^{* *}$ & $0.417^{* *}$ & $-0.387^{* *}$ & 1 & \\
6. Religious belief & $0.388^{* *}$ & $0.223^{* *}$ & $0.382^{* *}$ & $-0.177^{* *}$ & $0.519^{* *}$ & 1 \\
\hline
\end{tabular}

Note: Spearman's rank correlation analysis $\left(\mathrm{r}_{\mathrm{s}}\right)^{* *} p<0.001$

\section{Predictors of spiritual well-being}

Data showed that predicting factors of spiritual well-being were self-esteem $(\beta=0.264, p=0.000)$, social support $(\beta=0.386, p=0.000)$, and religious belief $(\beta=0.132, p=0.004)$. Religious belief, selfesteem, and social support together could explain $46.00 \%$ of the variance in spiritual well-being $\left(\mathrm{R}^{2}=0.46 ; p<0.05\right)$ (Table 5). The equation model of the standardized coefficient beta displays as follow:

$$
\mathrm{y}=0.264 \text { (Self-esteem) }+0.386 \text { (Social support) }+0.132 \text { (Religious belief) }
$$

Table 5 Multiple regression analysis for variables predicting spiritual well-being $(\mathrm{N}=395)$.

\begin{tabular}{lrrrrr}
\hline \multicolumn{1}{c}{ Variables } & \multicolumn{1}{c}{$\mathbf{b}$} & $\mathbf{S ~ E ~}_{\mathbf{b}}$ & $\boldsymbol{\beta}$ & \multicolumn{1}{c}{$\mathbf{t}$} & $\mathbf{p}$ \\
\hline Constant & -4.107 & 4.232 & & -0.971 & 0.332 \\
Self-esteem & 0.675 & 0.111 & 0.264 & 6.083 & 0.000 \\
Social support & 0.295 & 0.033 & 0.386 & 8.872 & 0.000 \\
Depression & -0.062 & 0.050 & -0.057 & -1.250 & 0.212 \\
Religious practices & 0.141 & 0.073 & 0.095 & 1.931 & 0.054 \\
Religious belief & 0.103 & 0.035 & 0.132 & 2.937 & 0.004 \\
\hline
\end{tabular}

$\mathrm{R}=0.68, \mathrm{R} 2=0.46, \mathrm{~F}=65.11, p<0.05$

\section{Discussion}

The findings of the present study revealed that the spiritual well-being of dependent older people was at a moderate level. Surprisingly, this was unexpected for this particular group. Older people whose physical condition is not good still have a good feeling toward self. This finding might be due to the effect of religious beliefs and practices, and all participants were Buddhist, Buddhism teachings help believers to see things as naturally happened. Another reason might be that most older people still lived with their families. Even though their marital status was mostly single or widowed, they still have a caregiver who was their child or neighbor, Also, in Thai culture, particularly in rural areas, people have close relationships with each other and will take care of each other. The findings support other previous studies that were done on independent participants. Previous studies found that the relationship between family or friends supports and spiritual well-being among older people [28].

Regarding spiritual well-being, the findings revealed that all variables including religious belief, religious practice, self-esteem, social support, and depression were related significantly to it. However, only three variables, that is, religious belief, self-esteem, and social support, could explain $46.0 \%$ of the variance in spiritual well-being among dependent older people. This finding partly supports the study framework that is guided by the Buddhism Principles, which proposed the relationship between spiritual well-being and all variables. In the present study, religious practice and depression could not explain the variance in spiritual well-being. Previous studies found that the predictor of spiritual well-being in older people was the religious practice $[16,19,29]$. Religious practice in the present study was found to have a positive relationship with spiritual well-being, but the findings did not reveal its ability to predict spiritual well-being. It might be the result of the relatively high coefficient value of the relationship between religious practice and religious belief.

Depression has a negative relationship with spiritual well-being for dependent older people. Older people have an understanding of the nature of life which changes all the time. Buddhist principles relate to natural laws of the universe, thus most of the older people feel peace of mind with hope and something 
to hold on to your heart. Especially, because Buddhist principles were brought into their lives, depression is reduced. These reasons help dependent older people view the world in reality that leads to solving problems about the causes of suffering according to the principles of Buddhism [14]. Similarly, the study of Namwong et al. found that spiritual well-being had a significant statistical negative relationship with depression $(\mathrm{r}=-0.416, p<0.001)[30]$.

Regarding the predictors of spiritual well-being in the present study, religious belief and social support are strong predictors. Social support is a basic necessity for older people to meet their physical, mental, emotional, and social needs, resulting in their satisfaction [31,32]. The older people receive social support in the form of love, commitment, concern, trust, financial support, goods, and information. Thus, older people experienced that they were part of society [33]. Receiving support from the network can make older people happy and lead to spiritual well-being. According to findings in the present study found that the overall social support scores of dependent older people at a moderate level. Most of the older people live with their spouses and children. This way of life is part of rural society and results in a hospitable community, so older people feel warm and safe. When the older people were sick or have distress, there were people in their community who were ready to help. This finding was consistent with the previous studies which showed a positive relationship between social support and spiritual well-being [19]. Perceived support from others makes people feel that they are valued and that they have good relationships with others. This helps to increase the sense of connectedness and thus to increase spiritual well-being. Moreover, previous studies found that social support is an additional factor that helps older people to control and solve their problems and social support correlated with the hope of the older people, which influenced the well-being of the older people. Those older people who were supported by family, neighbors, and friends were enabled to adjust to their suffering and to enjoy their lives.

Religious beliefs are attitudes towards various aspects of a particular religion. Buddhism focuses on personal spiritual development and the attainment of a deep insight into the true nature of life. Spiritual well-being is a peaceful state of mind that results from understanding truths about life and from having good relationships with others and with the self. The older people with a strong religious belief encourage appraisal of the problem as the challenges to lives with the conditions well. Moreover, previous studies proposed that stronger religious beliefs were positively correlated with spiritual wellbeing [34]. This was in accordance with the study which found that older people with less chronic illness have a high level of spiritual wellbeing (92.2\%), the researcher explained that the teachings of the Buddha can be used in life to understand their suffering from illness [35]. The faith in religion helps older people to continue in their peaceful way of life. According to the Buddhist doctrine that "reliance on one's self" means knowing, understanding, accepting, and being able to live with the truth of life in self-sufficiency because religion was the principle and method that humans choose to use in their lives. Buddhist practices, especially threefold training helps older people to feel calm and comfortable, relaxed, happy, strong in their spirit, and spiritual well-being.

Self-esteem was defined as the feeling of self-value and selfrespect and was found to be related possibly to spiritual well-being [36]. This research finding indicated that self-esteem is a predictor of spiritual well-being, which the previous studies found was a defining attribute that is meaningful, valuable, proud, and enables a peaceful life [37]. Moreover, the studies, proposed that a happy life that is based on self-esteem and from positive thoughts about illness and suffering helps the older people not to feel suffering from an illness because they think that the illness adds strength to their thoughts and feelings that life is really happy and that one should be mindful and control one's own emotions [35]. This feeling leads to a happy life and strong spiritual well-being. In addition, the previous studies identified the relationships among self-esteem, meaning in life, and spiritual well-being in middle school students and found that there were significant correlations between self-esteem and spiritual well-being [38]. Moreover, the studies, involving as participants 322 undergraduates at the University of Tehran, found that self-esteem was a partial mediator of the spiritual well-being relationships [39].

As the present study demonstrated that only $46.0 \%$ of the variance in spiritual well-being among dependent older people was explained by the three variables. Therefore, there were still other potential variables in this phenomenon that influenced spiritual well-being among dependent older people. The previous studies about predicting the spiritual well-being of older people with chronic illness showed that religious practice $($ Beta $=0.33, t=5.73)$, instrumental activities of daily living $($ Beta $=-0.24, t=-3.16)$, and the severity of the disease (Beta $=-0.14, \mathrm{t}=-2.55)$ (Mongkhonittivech and Yeammisri, 2016) were significant predicting factors, which as a set of factors differs from the findings of this study. 


\section{Conclusions}

The purpose of this cross-sectional predictive correlational study was conducted to examine the level of spiritual well-being among dependent older people, to examine the relationship between religious belief, religious practice, self-esteem, social support, depression, and spiritual well-being and identify predictive factors of spiritual well-being of dependent older people. The conceptual framework is guided by the Buddhism Principles. The participants were 395 Thai people aged 60 years and above who are dependent. The research instruments included The Spiritual Well-Being Scale for Dependent Older People, Thai version of the Rosenberg Self-Esteem Scale, Thai version of the Multidimensional Scale of Perceived Social Support, Thai Geriatric Depression Scale, The Religious Practices Questionnaire, The Buddhist Belief Questionnaire, and The Demographic Data Form. The content validity index of the Spiritual Well-Being Scale for Dependent Older People was examined by a panel of six experts and reported to be 0.97 . The reliability coefficients of all research instruments were acceptable from 0.80 to 0.97. Data were analyzed using descriptive statistics, Spearman's rank correlation coefficient, and multiple regression analysis. The results are demonstrated as (1) the spiritual well-being among dependent older people was at a moderate level $(\overline{\mathrm{x}}=46.97, \mathrm{SD}=7.22)(2)$ Religious belief, religious practice, self-esteem, and social support significantly related positively to spiritual well-being $(p<0.01)$, while depression significantly related negatively to spiritual well-being $(p<0.01)$ and (3) Religious belief, self-esteem, and social support together could explain $46.00 \%$ of the variance in spiritual wellbeing.

The limitation of this study is that the sample was selected only from three provinces in the southern part of Thailand, thus, this may limit the generalizability of the findings of spiritual well-being among Thai dependent older people. The recommendations for further study are demonstrated as the experimental studies to test the effects of a program for enhancing spiritual well-being should be planned based on the predicting factors. The program focuses on enhancing social support as well as self-esteem and religious belief should be planned and tested on the outcome of spiritual well-being.

\section{Acknowledgements}

The researcher gratefully acknowledges the support provided by the Faculty of Nursing, Chiang Mai University, Thailand and thanks all the participants in this study.

\section{References}

[1] United Nations Department of Economic and Social Affairs. World population ageing 2019. United Nations, New York, 2019.

[2] National Statistical Office. Social indicators 2017. Ministry of Digital Economy and Society, Bangkok, Thailand, 2017.

[3] B Sririphanich. Situation of the Thai elderly 2016. Foundation of Thai Gerontology Research and Development Institute, Bangkok, 2016.

[4] National Health Examination Survey Office 2016. Thai people's health survey plan, Available at: https://kb.hsri.or.th, accessed July 2018.

[5] P Comin. 2005, Experiences of care receiving of dependent elderly by family caregivers. Master's thesis. Chulalongkorn University, Bangkok, Thailand.

[6] BR Ferrell, M Grant, B Funk, S Otis-Green and N Garcia. Quality of life in breast cancer Part II: Psychological and spiritual well-being. Cancer Nurs. 1998; 21, 1-9.

[7] CW Ellison. Spiritual well-being: Conceptualization and measurement. J. Psychol. Theol. 1983; 11, 330-40.

[8] LS Chapman. Developing a useful perspective on spiritual health: Well-being, spiritual potential and the search for meaning. Am J. Health Promot. 1987; 1, 31-9.

[9] RF Paloutzian and CW Ellison. Loneliness, spiritual well-being and the quality of life. In: LA Peplau and D Perlman (Eds.). Loneliness: A sourcebook of current theory, research and therapy. John Wiley and Sons, New York, 1982.

[10] P Payutto. Buddhadhamma. 10 ${ }^{\text {th }}$ eds. Dhamma Council, Bangkok, Thailand, 2003.

[11] ME O'Brien. Spirituality in nursing: Standing on holy ground. $2^{\text {nd }}$ eds. Jones and Bartlett Publishers, Sudbury, Massachusetts, 2003, p. 84-6.

[12] T Khemaweero, T Pattanasing, T Khankaew, K Khumtua, and S Lapontan. Enhancement of elder people's spiritual well-being according to Buddhism doctrines. Mahachulalongkornrajavidyalaya J. Univ. Peace Stud. 2017; 5, 78-88. 
[13] T Tongprateep. Spiritual health promotion. Thai J. Nurs. Coun. 2003; 17, 51-61.

[14] S Promkaewngam. 2013, Development of the spiritual well-being scale for Thai Buddhist adults with chronic illness. Ph. D. Dissertation. Chiang Mai University, Chiang Mai, Thailand.

[15] K Limsup and T Surinya. 2014, Self-awareness, optimism, life satisfaction and spiritual well-being of the elderly at the senior service center Din Dang, Din Gang Bangkok. Master's thesis. Bangkok, Thailand.

[16] U Chaichanawirote. 2000, Relationship among family relations health status Dhamma practice and spiritual well-being of the elderly. Master's thesis. Burapha University, Chonburi, Thailand.

[17] C Sinchawanichakul and J Kespichayawattana. Factors related to healthy aging among the older persons in community-dwelling of Bangkok Metropolitan. J. Roy. Thai Arm. Nurs. 2016; 9, 100-9.

[18] S Nidanunchai and M Suntithirasak. Social support and environment that affect the care of the elderly in Samut Prakan province. J. Nurs. Div. 2010; 37, 64-72.

[19] W Thuntitrakul. 2009, Factors related to spiritual well-being of terminal cancer patients. Master's thesis. Chulaiongkorn University, Bangkok, Thailand.

[20] RL Kahn, AI Goldfarb, M Pollack and IE Gerber. The relationship of mental and physical status in institutionalized aged persons. Am. J. Psychiatry. 1960; 117, 120-4.

[21] T Yamane. Statistics. An introductory analysis. $2^{\text {nd }}$ eds. Harper and Row, New York, 1967.

[22] P Srisaeng. Self-esteem, stressful life events, social support, and postpartum depression in adolescent mothers in Thailand. Case Western Reserve University, Ohio, USA, 2003.

[23] P Boonyamalik. Epidemiology of adolescent suicidal ideation: Roles of perceived life stress, depressive symptoms, and substance use. Johns Hopkins University, United States, 2005.

[24] Train the Brain Forum Committee. Thai geriatric depression scale-TGDS. Siriraj Med. J. 1994; 46, $1-9$.

[25] S Seesopon, L Pothiban and N Suwankruhasn. Buddhist beliefs and caregiving burden among caregivers of older persons with congestive heart failure. J. Nurs. Educ. 2017; 10, 56-70.

[26] F Marhoney and D Barthel. Functional evaluation: The barthel index. Maryland State Med. J. 1965; 14, 61-5.

[27] JF Hair, WC Black, BJ Babin and RE Anderson. Multivariate data analysis. $7^{\text {th }}$ eds. Upper Saddle River, Prentice Hall, New Jersey, 2010.

[28] S Pincharoen and JG Congdon. Spirituality and health in older Thai persons in the United States. Western J. Nurs. Res. 2003; 25, 93-108.

[29] N Mongkhonittivech and W Yeammisri. Factors predicting spiritual well-being among the elderly with chronic illness. Nurs. Sci. Health J. 2016; 39, 1-11.

[30] A Namwong, A Khampeera, W Chaijundee, and K Laongon. Selected factors related to depressive symptoms among community-dwelling older people with chronic illness. Nurs. Public Health Educ. J. 2018; 19, 94-105.

[31] S Cobb. Social support as a moderator of life stress. Psychosomatic Med. J. 1976; 38, 300-14.

[32] RS Weiss. The provisions of social relationships. In: Z Rubin (Ed.). Doing unto others. Englewood Cliffs, Prentice-Hall, 1974, p. 17-26.

[33] JS House. Work stress and social support. Prentice Hall, New Jersey, 1981.

[34] E Colón-Bacó. The strength of religious beliefs in important for subjective well-being. Undergraduate Economic Review. Available at: http://digitalcommons.iwu. edu/uer/vol6/iss1/11, accessed July 2018.

[35] S Promkeawngam and A Namwong. The spiritual well-being of community- dwelling Thai older people with chronic illness. Nurs. Health Care J. 2017; 35, 204-13.

[36] M Rosenberg. Society and the adolescent self-image. Princeton, Princeton University Press, 1965.

[37] N Suwan, S Kantawang and S Lirtmunlikaporn. Concept analysis of spirituality. Rama Nurs. J. 2018; 24, 1-12.

[38] KA Kang, SJ Kim and MK Song. Relationship of self-esteem, meaning in life, and spiritual wellbeing in middle school students. Child Health Nurs. Rese. 2009; 15, 343-9.

[39] M Joshanloo and F Daemi. Self-esteem mediates the relationship between spirituality and subjective well-being in Iran. Int. J. Psychol. 2014; 50, 115-20. 